\title{
No Mar dos Abandonos \\ suspiro entre a teoria e prática queer
}

\author{
Sara Wagner Pimenta Gonçalves Júnior ${ }^{1}$ \\ O artista é uma mera ficção acrescentada à obra - a obra é tudo
}

Nietzsche

Percebo-me hoje como uma privilegiada, mesmo tendo sido uma criança criada por uma avó paterna adotiva, que me criou até os 8 anos como tendo laços de consanguinidade. Entretanto, fui retirada ainda recém nascidx de um hospital em dezembro de 1975, por uma mãe que já tinha quatro filhos e precisava de mais um filho, desta vez para a formação de sua nova família, com o então amante. Percebo que aqui a narrativa toma traços que vão definir o perfil do meu maior inimigo nas táticas sociais de sobrevivência: o patriarcado!

Eu fui a promessa e expectativa de família feliz, cisgênero, heterossexual e $100 \%$ normalizada, isto é, compreendida como normal, como natural pelo processo daquilo que nossa constituição entende como família. Entretanto, falo de uma família composta por três pessoas, um amante que acredita ser pai biológico de um filho do sexo masculino, uma mulher, mãe de quatro filhos, que aparece com um recém nascido do sexo masculino, e um recém nascido que foi retirado de sua progenitora por meios ilícitos. Sendo esta família uma estrutura falsa, mentirosa e sem sentimentos reais por parte de alguns atores, esta foi feita e compreendida para recriação de desenhos lineares e sem distorções, mas então esse recém nascido cresce e reage diariamente. Chamo a atenção nesse momento para os sentimentos possíveis de uma "mãe" que sequestra um recém nascido para ser parte de uma invenção, e esta ter que diariamente ver esse filho como prova de um crime, o sequestro cometido. Cresci assim, sendo a pior coisa que poderia estar diante de uma mãe, e por anos tentava compreender o porquê de tanto mal estar diante desse filho.

Sou latina de cabelo preto e enrolado, quase compreendida como mestiça, mas que em função de anos de cabelo pintado de loiro claro e alisado, fui me distanciando do qualificador de negritude que possuo, o cabelo que me qualifica como branca e um nariz cirurgicamente

\footnotetext{
${ }^{1}$ Professora, ativista LBGTQIA, formadora de atores, linguista, tradutora, pedagoga e pesquisadora.
} 
desenhado para que pareça menos mestiça ou negra. A compreensão do colorismo que sempre funciona como marcador fiel para e nas inserções sociais. No Brasil, terra de miscigenação extremada e não reconhecida por sua negritude, aos quarenta e dois anos, me encontro com boa sobrevida, uma vez que, segundo as estatísticas da ANTRA, a vida de mulheres transexuais no Brasil é de trinta e cinco anos em média. Nunca conheci minha progenitora, e chamo de mãe a mulher que me roubou no hospital há 43 anos atrás.

Gosto de arroz com qualquer coisa e não como fígado nem abóbora, graças a ela, que quase diariamente mandava uma babá me alimentar e dizia que era para "virar um homem grande e forte", o deboche e o ar de desdém, era um companheiro diário em suas falas.

Aos onze anos já me sentia "Sara" e a confirmação vinha de minhas conversas por longos períodos de tempo, diariamente, com homens mais velhos em chats de bate-papo telefônico. Eles, os homens e o bate-papo, confirmavam a mulher trans precocemente erotizada (pelo círculo social e familiar no qual estava inserida), que eu viria a ser.

O primeiro estupro foi sofrido em 1986, perpetrado por um parente muito próximo. Senti vergonha, medo e culpa, mas decidi que seria bom se contasse para minha mãe. Naquela mesma semana, fiz o relato sobre o ocorrido, recebi um bofetão na face que me fez calar e ela apenas disse: Nunca mais repita isso, você quer acabar com a minha família?

De fato, não disse isso para ninguém por mais de duas décadas...

Fui definida como "viado" e foi dessa forma grosseira e no padrão de insultos que começo a perceber-me, nas vivências e reflexões nesse CIS-tema. O termo "viado" foi ouvido por anos, talvez até os dias de hoje, uma vez que a transição corporal somente se iniciou por volta dos 20 anos. Mesmo usando sandálias femininas desde muito jovem, talvez 12 ou 13 anos. A sociedade me definiu com o insulto e somente anos depois pude realmente compreender que pertencia ao grupo de excluídos, por ser/estar em uma expressão de gênero que não cabia dentro da linha concordante entre sexo biológico masculino e performatividade (BUTLER, 2003) numa compreensão de construção de si no gênero do qual eu não sou ou era pertencente.

$\mathrm{Na}$ verdade, eu não nasci estranha, nasci bebê, depois criança, mas era perceptível como a sociedade trabalhava de forma a excluir com brevidade e de modo definitivo quem dela ou nela causasse estranheza ou transgredisse suas regras.

Em nossa sociedade, a norma que se estabelece, historicamente, remete ao homem branco, heterossexual, de classe média urbana e cristão e essa passa a ser a referência que não precisa mais ser nomeada. Serão os "outros" sujeitos sociais que se tornarão "marcados", que se definirão e serão denominados a partir dessa referência. Desta forma, a mulher é representada como "o segundo sexo" e gays e lésbicas são descritos como desviantes da norma heterossexual. Ao classificar os sujeitos, toda sociedade estabelece divisões e atribui rótulos que pretendem fixar as identidades. Ela define, separa e, de formas sutis ou violentas, também distingue e discrimina (LOURO, 2001, p. 09). 
Ainda criança ouvia minha mãe, mulher "bela, recatada e do lar", mas também sagaz em negócios e comércios, falar coisas do tipo, - "aqueles maconheiros, aqueles viados, aquelas putas, aqueles pretos, aqueles sujos, aqueles vagabundos, aquela gente”, Eu sempre pensava, "Mãe, eu poderia ser um deles", mas logo entendi de que lado eu estava e que eu não ditaria as regras dessa caminhada, com minhas micro-táticas de sobrevivência, a não ser que me tornasse maior e dona de minha própria fala. Esse escape, nos anos 1980, 1990 e meados dos anos 2000, era quase impossível de ser visto, lido ou sentido. A invisibilidade era imensa e o assunto Transexualidade e Travestilidade, tabus que ainda hoje perduram e são reforçados em todo país, através do reverberar dos discursos fascistas, de fundamentalistas religiosos e de apelo fácil às políticas neoliberais, em função da (des)informação crescente da população, através e com apoio das mídias, como vemos nos apoiadores do MBL, da Direta (política) e do Escola Sem Partido, por exemplo.

O período escolar foi marcado por infinitos abusos de professores, diretores e colegas, uma vez que toda a simbologia do feminino era identificada nos meus primeiros passos, seja nos afetos, ou no comportamento, nas expressões (de gênero). O ser doce, educado, cortês, amigável, empático e todas as características do mundo sensível ganhavam significados de feminilidade diante da demanda heteronormativa ali estabelecida. Deste modo é perceptível que todo desejo/compreensão de sexo, sexualidade e identidade de gênero deveriam se dimensionar dentro dos moldes da heteronormatividade, sendo esta a única orientação sexual considerada "normal" e aceita. Entretanto, ao assumir tais verdades, coloca-se LGBTTQIA+ dentro de perspectivas de marginalização e práticas LGBTQIA+fóbicas. Permanecer sendo polido era uma aventura, por vezes, complexa, pois a melhor forma de ser introduzido como "viado", nas rodas de conversas familiares, era com os comentários das "tias": "Vejam como esse menino é educado!" Ao ouvir, eu sempre olhava para o rosto do homem ou dos homens presentes e via neles o olhar sarcástico de abutres detentores de verdades absolutamente inquestionáveis que, aliás, eu lia como "poder", porque, ao permitir o abuso, tornava-me parte do interesse deles e, então, qualquer acusação não poderia dali advir, pois não eram mais acusadores, tornavam-se cúmplices.

Lembro que minhas conquistas e boletins escolares durante minha infância eram sempre compartilhados e comemorados com a babá-escrava, Tereza Minervina. Ela foi tirada da roça, levada dos pais aos doze anos, quando eu tinha uns oito, na desculpa de que seria tratada como filha pela minha mãe. Lembro que senti pena e angústia, ao vê-la se despedindo da mãe, no meio do cerrado, em busca de novas expectativas na cidade grande onde morávamos e para onde estava indo. Ela era uma escrava "branca de cabelo duro", trabalhava 
na minha casa, sem salário ou qualquer tipo de apoio. Eu tive meus primeiros ensaios na docência ali. Ensinei Tereza a ler e escrever com meus livros, numa espécie de repasse de lição. E todas as minhas vitórias de infância sempre foram celebradas com ela e por ela. Eu tinha direito à escola paga e ela à alimentação, mas sentia a pressão da impossição e dor da opressão sempre que meu pai saia para o trabalho e ficávamos apenas eu, Tereza e aquela "minha" mãe.

Enquanto as sufragistas iniciaram sua caminhada no início do século, apenas em meados dos anos 1980, a América Latina e, particularmente o Brasil, dão início a essa compreensão. Caminhávamos por uma explosão de imagens e cores que buscavam trazer a concepção dos movimentos estrangeiros durante a moderada vida pós-ditadura na qual estávamos inseridos.

Aos dezesseis anos entrei no Curso Superior de Enfermagem. Além disso, dançava Balé Clássico e fazia Teatro na escola, mas foi na universidade que descobri, com a ajuda dos colegas, o poder dos hormônios. Iniciei a ingestão por conta própria nessa época. Mesmo com a modificação externa, foi naquele momento que tive minha primeira experiência sexual com uma mulher, e isso foi cheio de expectativas é claro, por compreender-me como heterossexual e transexual. Foi um tanto frustrante, uma vez que aquele sexo era livre de culpa, a heterossexualidade como normal, o modo permissivo da heterossexualização compulsória. Era calmo e menos "arrebatador". Essa relação lésbica deu-me um filho, fruto de um relacionamento rápido de pouco mais de três meses. Ele nasceu no ano seguinte, em junho de 1992.

A carga extremada da religião e das subjetividades do "Sagrado e Profano" povoaram minha mente por anos desde a infância, onde a colonização religiosa tem início em toda criança (ou quase todas) e o desejo de me livrar desse peso, dos padrões, passa a ser o alvo nessa caminhada onde todos me julgavam, até deus. O medo do inferno me acompanhou até os vinte e poucos anos, e livrar-me desses preceitos foi, grosso modo, a maneira mais ampla na construção de um caráter real, livre e protagonista. Se o sexo lésbico permissivo era leve, o sexo com homens, praticado por uma mulher trans era extremamente intenso, "sujo" e satisfatório.

Os homens amam os homens. Eles nos explicam o tempo todo o quanto amam as mulheres, mas todas sabemos que isso é bobagem. Eles se amam, entre eles. Eles transam uns com os outros através das mulheres, muitos dentre eles já pensam nos amigos quando se encontram dentro de uma buceta. Eles se observam no cinema, eles se reservam os melhores papéis, eles se acham poderosos, eles se gabam, não conseguem se conter por serem tão fortes, belos e corajosos. Eles escrevem uns para os outros, eles se parabenizam, eles se apoiam. Eles tem razão. Mas de tanto escutar eles se queixarem de que as mulheres não trepam muito, que elas não amam o sexo como deveriam, que elas nunca entendem nada, não podemos evitar de perguntar: o que eles estão esperando para fuder uns os cus dos outros? Vão em frente. Se isso fará de vocês homens mais sorridentes, é uma coisa boa. Mas, entre as coisas que lhe 
foram corretamente inculcadas, existe o medo de ser gay, a obrigação de amar as mulheres. Então, passam longe das outras coisas. Reclamam, mas obedecem. De passagem, batem em uma garota ou duas, furiosos por se sujeitarem (DESPENTES, 2016, p. 118-119).

A identidade trans, da compreensão que passo a assumir e entender de mim mesma, foi sendo construída no passear por vários mundos. De trabalhos artísticos que ganharam reconhecimento nacional e foram aplaudidos pelo Brasil - como Meu Guri, de Chico Burque, 1994, sendo secretário de Governo no Centro-Oeste em 1998, e padrinho de vários casamentos enquanto portador de uma identidade cisgênera, mas ainda que homossexual ou lida desta forma por quem a visse. Então, a reflexão que me norteia nesse momento do texto é, como poderia ser "homem", se tais padrões balizadores dessa performance são validados por outros "homens" numa estrutura ideológica identitária de algo que não se pode medir ou (de)limitar, pois está predeterminada por outros, na forma como se auto validam em suas ações.

A partir do momento em que a identidade transgenerificada foi assumida, todas as portas se fecharam. Serviços que perpassem pelo CIStema social, e dos poderes Executivo, Legislativo e Judiciário, que expressavam um panorama de incertezas legais e morais, dentro do universo cis-binário, já no mundo trans, os abusos são maiores. Então, busco um universo que se contraponha à seriedade da composição de uma cultura política, que adote a livre expressão da orientação sexual e de gênero, transcendendo os parâmetros calcados em valores da norma "heterocêntrica".

Em 1999, concomitantemente às transformações nas vestimentas que vivenciava, fui retirada de um espaço público, após usar o banheiro feminino. Depois de um exaustivo processo que durou dois anos, fui obrigada pela sentença da Exma Juíza e pastora da Igreja Sara Nossa Terra, a pedir desculpas ao gerente do estabelecimento e pagar duas cestas básicas por entrar em um banheiro feminino sendo "homem", mesmo usando vestido e salto alto e possuindo, segundo ela, caraterizações do universo feminino, mas ainda assim, sendo um homem de sexo masculino. Mas por que usei naquele momento o banheiro feminino? Não apenas pela condição estética reconhecida pela sociedade, mas, principalmente, pelo desenho geométrico e espacial de um banheiro feito para ser privado, como é o caso dos banheiros femininos. E não um ambiente de comparações de poder, como pode ser visto nas fileiras de mictórios, os vulgos "coxinhos", que são lugares nos quais os homens se esmeram na observação, constatação ou comparação de seus falos durante sua micção. Acredite, ter um pênis acima da média, um "pauzão", no mundo cis-heteronormativo machista, faz toda a diferença. Enquanto transexual e portadora de falo, nesse momento uso falo, pela inserção e compreensão psicanalítica que aqui emerge, pois possuir tal adereço pode ser mais complexo, 
vexatório e desafiador, principalmente se o seu uso não perpassa pelas ementas do poder cisgênero, machista, falocêntrico e patriarcal. É como ser portador de um "troféu" que na sua mão não lhe dá méritos, apenas ônus.

Em 2003, trabalhando no Salão de Beleza que transformou-se em refúgio e meio de vida, um homem chamou-me de "frutinha". Perguntei-lhe se gostaria de "chupar a fruta", colocando a mão sobre a genitália. Ele, então, aproximou-se de mim e desferiu um soco em meu rosto. Após quase dois anos, durante o desfecho da sentença final, uma juíza condenoume a pedir desculpas a ele, por ter cometido o absurdo de constrangê-lo ao "apalpar a genitália em ambiente público diante de um transeunte".

Em 2004, mudei-me para a cidade de Londres, onde inicio entre outras atividades, o trabalho junto a ONG Sahir House de ajuda a população refugiada que vivia com HIV, e junto a ONG White Chappel de ajuda a população de rua e dependentes químicos.

No ano de 2010, conheci duas irmãs gêmeas refugiadas, recém-chegadas das zonas de conflito, no "The Royal London Hospital”. Em serviço voluntário, fui dar meus votos de melhora e acolhimento. Eram, na verdade, três irmãs, as gêmeas de dezesseis anos e uma irmã mais velha de dezoito anos. As gêmeas foram retiradas de um campo, onde viveram e foram violentadas por quase seis anos por vários soldados das forças armadas que ali atuavam. Os estupros coletivos aconteciam várias vezes ao dia. Seus ligamentos foram cortados junto com as suas línguas, e a mais velha foi poupada para alimentar as duas mais jovens que, na época inicial contavam com pouco mais de nove anos de idade. Esse evento resume o que houve com a minha crença em deuses, e a partir dele, passo a me apresentar como ateia, livre de crença em deuses ou outras forças de natureza não comprovada pela ciência e outros métodos.

No final de 2013, em razão de querer estar mais próxima do meu filho, morador do Brasil, e desejo de ser ativista como era no Reino Unido, ingressei numa segunda licenciatura, desta vez em Pedagogia, com intenção de ressignificar minha existência, caminhada e ativismo. Junto com o vestibular da Universidade do Estado do Rio de Janeiro, fui aprovada no mesmo ano, no concurso público municipal na cidade de São Pedro da Aldeia, também no Estado do Rio de Janeiro, para o cargo de professora de Teatro.

Em setembro de 2016, um colega professor colocou uma matéria de um site evangélico no grupo de trabalho do Whatsapp, falando sobre a "Proibição do casamento gay" (por algumas vezes). Senti-me constrangida, uma vez que apenas cis héteros compunham aquele grupo, e fiz a devida correção em algum momento sobre o fato, explicando a inverdade contida no texto, era um texto falacioso que trazia aspectos perpassados por práticas fundamentalistas. $\mathrm{O}$ colega revidou, falando que era contra o casamento gay por não ser de deus. Respondi que o que ele achava deveria ser usado em sua casa, uma vez que a lei 
garantia igualdade à população LGBT. Após o incidente, recebi uma advertência escrita das mãos da diretora da escola que, juntamente com os representantes do Conselho Escolar, disseram-me para entender que aquilo não era normal!

Enquanto professora, observo, assim como Paulo Freire, que os resultados falam muito, mas as práticas falam muito mais que as teorias. Então, temos, de um lado, professores, mestres e doutores num diálogo vertical que cada vez mais aprofunda visões e, do outro, alunos e pais que mal reconhecem a sua função de manutenção de condições mínimas para a inserção na sala de aula que possa incluir estudantes num ciclo diário de reconstrução A minha mãe, por exemplo, que vem do interior de Goiás, se dedicava a me fazer falar como os "machos falavam" e, quando eu voltava para casa com inflexões dos tempos verbais aprendidas - por exemplo, "nós voltaremos" - era comum servir de chacota dos meus irmãos, por falar daquela maneira.

Penso que para compreensão desse amontoado de histórias, seja necessário que se perceba, que o fluxo contínuo da/na educação teve seus efeitos e calou muito de nossa transhistoricidade. Percebo meu próprio ato escrito, arrolado em um discurso mediano, que mais denuncia que explica e pouco conforta quem está em busca de uma possível paz. Esse "repensar", que ainda se faz necessário para criar um mundo menos desigual, é trazido aqui, para que a qualquer momento, alguém que seja curioso das formas escritas-pensamento de uma mulher trans/travesti, deficiente visual e disléxica com formação em linguagens, se desenvolvam. Para que outras possam beber dessa fonte e se lançar na descoberta de suas próprias limitações em outros momentos de contraditoriedade cíclica histórica, que de tão amplas se tornam pequenas ao serem contrastadas com as do outro, em um outro momento, de uma outra forma.

Ao iniciarmos as atividades do grupo de trabalho e pesquisa em Gênero e Sexualidade, no início de 2016, na Universidade Estácio de Sá - Cabo Frio, sob supervisão e orientação da Professora Doutora Adriana Gleiser, muitas histórias vieram à tona, como nessas memórias que trouxe aqui, ou a partir da percepção da necessidade de uma bibliografia feita por mulheres transexuais e travestis na/da leitura acadêmica, uma vez que a grande maioria das pessoas simplesmente não sabia de que forma agir diante de minhas experiências de infinitos abusos e estigmas cruzados, mesmo naquele grupo, talvez por não ser o centro daquelas discussões. Sendo filhos oriundos dessa cultura de berço patriarcal (machista, sexista e misógino), muitas de nossas construções sempre passam pela dinâmica de regras e estruturas pré-criadas a partir desses conceitos, nesse grupo. Diante de tantas indagações também experimentei, através das discussões, a necessidade de costurar este enredo teórico à vivência de meus quarenta anos, sendo "elenco de apoio" e/ou objeto de estudo. 
Era hora de tornar-me protagonista, sobretudo nas falas acadêmicas ricamente apresentadas por meus pares cisgêneros e que falam de dor, mas sem jamais saberem dessa intensidade.

Sendo a transexualidade, a condição em que o gênero de uma pessoa (aquele percebido por ela ou sentido por si) não corresponde com o que lhe foi designado ao nascer com base em sua genitália. Hoje sabemos que pode não ser binária em sua formação (masculino, intersexual e feminino). Logo, como responder por tamanho "distúrbio", sendo que, visto do ângulo de quem se expõe, essa conjunção não obedece às regras da heteronormatividade? Como, sendo "morcego" poderia ser analisado como ave? E foi isso que a religião nos fez, quer dizer, ela estabeleceu limites em seus discursos que nos ataram às suas regras. As regras binárias e suas nomenclaturas passam por modificações extremadas ao nos depararmos com portadores de corpos trans não-binários e pessoas intersexuadas, ou seja, seres humanos intersexos são ou apresentam qualquer variação de caracteres sexuais incluindo cromossomos, gônadas e/ou órgãos genitais que dificultam a identificação de um indivíduo como totalmente feminino ou masculino, e é baseado nessa chave que ampliamos a compreensão no âmbito da biologia, genética e suas binaridades assumidas durante anos como pressupostos normativos mantenedores do nosso CIStema ou sistema cisgênero.

Vestimos esses corpos-pensamentos, que nos disseram que eram certos e vivemos a vida como se aquela regra fosse a nossa, como se fosse eterna, mas regras são feitas para uma "adequação e melhor forma de convívio". Sempre deve-se repensar sobre as regras depois de utilizadas por certo tempo ou depois de percebidas como excludentes em sua dinâmica. Uma mulher divorciada nos anos 1970 era uma "piranha”, e segundo a Bíblia, ela seria uma vítima potencial de apedrejamento. Mas no mundo das regras, isso tem mudado, e o direito de ser feliz deveria vir em primeiro lugar. Hoje, apesar disto não ser garantido, já podemos percebêlo como possível algum dia, mesmo diante dos praticantes "desse" cotidiano.

Arlette Farge (2009), quase que antropofagiando Michel Foucault, afirma que a violência possui uma racionalidade. É por isso que a preocupação não pode ser mais “combater a razão-desrazão no momento em que se exerce a violência, mas analisar a natureza da racionalidade que produz essa violência a fim de transformar eventualmente o seu (dis)curso" (FARGE, 2009, p. 35). Ou, ainda, "[é] preciso então compreender as formas de racionalidade que fazem jorrar (e justificar) a violência” (FARGE, 2009, p. 39). Estamos no vácuo das ações, pessoas que sabem muito e não dão as mãos a outras pessoas, que nada sabem sobre conceitos tão bem propagados em nossos encontros técnico-científicos.

Não! Nós não sabemos o que fazer com as informações antigas tão vestidas e vividas em nossas falas, e isso também é muito novo, porque enquanto os posicionamentos políticos 
Queer me permitem a expansão do meu corpo como sendo meu, o que fazer com uma série de conceitos que ainda me amarram e me tornam tão amante desse CIStema? As buscas por estruturas inteiras de amarras do meu $\mathrm{Eu}$ e Id, numa luta infinita para justificar aquele Superego, a pessoa que tenho me tornado ou busco encontrar na auto-imagem de alguém que busca a auto aceitação. Isso traz a completa compreensão da Síndrome de Estocolmo, que aplica à vitima um apelo emotivo e de amor ao seu carrasco, de modo que sua manutenção se torna visceral e "quase” indissociável, e mesmo compreendida, pode ser inalienável. Isso é ser trans no inicio desse século, sobretudo no Brasil.

Sabemos que no mundo tudo é signo. Logo, o que penso, o que falo e como sinto, estão diretamente ligados à proposição e compreensão desse mundo vivido e lido pelas minhas experiências prévias e que diuturnamente me permitem a plena aceitação do "Eu sou".

Gênero é algo que se aprende a ser, a partir das perceções das construções que existem. Sexo é biológico e performativo por ser binário (masculino e feminino), uma vez que esse binarismo ignora pessoas que não fluam nessa regra, como os indivíduos intersexuados ou gênero-diversas aqui mencionados. Gênero é um modelo de que não se tem o original, porque todos são cópias de um anterior inquestionável até então, como nos diz Judith Butler (2001) em suas colocações, somos e sustentamos a cópia, da cópia da cópia ou encenação dela, “...é a matriz que torna possível toda intenção prévia, sua condição cultural possibilitadora" (BUTLER, 2001, p. 155).

Ao entrarmos no gueto e suas reproduções, vemos que a aceitação em teoria nos dá uma cobertura, por sermos vistos como cópias que bem se relacionam em suas performatividades. Das funções sociais, essas distâncias ganham amplitude, quando o indivíduo migra de cis para trans. O sentido desse migrar pode ser ampliado quando esse sujeito trans, por exemplo, na pré-adolescência, identifica-se com o mundo homossexual, o que acaba sendo um grande complicador em seu início de caminhada, visto que apesar de ver se "homossexual" ele/ela, na verdade ainda pode não se perceber transexual, por não saber suas nomenclaturas, mas não por não saber quem se é, o que nos leva novamente ao mundo dos signos.

Transgênero no Brasil possui formas de compreensões restritas. Travesti, nome made in Brazil, com conotação de prostituição e subversão, desenhado por Harry Benjamim (1966), ou seja, na década de 1960, e "transexualismo" que assume inicialmente uma dimensão de doença. Para Michel Foucault (1988), então, a afirmativa de que ou se é doente ou se é prostituta, num mundo de transgressores, em que o que somos é colocado dentro de padrões por outros estabelecidos, e novamente o que "Eu sou" passa novamente a ser a conclusão de outros e não minha. 


\section{Finalizando as compreensões de teoria à prática!}

Posso retornar à criança sequestrada no início de minha "contação", para trazer a ampliação das dinâmicas atribuídas nas táticas de sobrevivência, mas percebo que existem formas de pensamentos e suas construções cristalizadas (DELEUZE, 2007) em como concebemos os corpos, mas tudo isso se inicia a partir do "cânone" binário imposto e impostor que foi ficando cada dia mais presente. Em uma forma de compreensão menos fluida, determinante e mais questionadora dessas análises, proponho o repensar desta e destes praticantes do cotidiano (DE CERTEAU, 2007), que buscam ressignificar o pensamento de pessoas em todas as suas instâncias por mais excluídas ou protagonistas que se sintam, uma vez que a questão da construção e sua produção (de verdades e de gentes, inclusive), somente é possível porque existe um agente por trás do gênero imposto e que sugere que sejamos isso ou aquilo, enquanto na verdade, esse deveria ser o chamamento para que desconfiemos dessa noção. Pois, se o gênero é construído, isso não significa necessariamente que seja construído por um "eu" ou por um "nós", mas por um "alguém" anterior a construção, uma produção, e ainda, protagonista ou coadjuvante ao gênero e seu processo. O indivíduo enquanto "Eu", não está nem antes nem depois do processo de "ser macho ou fêmea", isso quer dizer que esse “eu” emerge mesmo no interior, como único, refletido e reflexivo no indivíduo em questão e em suas relações de gênero, de observação e produção de pares/parceirxs.

A "contação" deste relato, em que se constitui a narrativa do "eu", citando, "O subalterno pode falar?”, da professora indiana Gayatri Spivak:

Essa tradição defende que há diferentes 'efeitos de verdade' a depender de quem
enuncia um discurso. [...] um homem branco rico e mais velho é ouvido com mais
atenção e seus argumentos são mais considerados dos que aqueles de uma mulher
jovem, negra e pobre [...] há uma espécie de contradição performativa, ou seja,
embora um homem branco possa estar denunciando o racismo e o machismo, a sua
própria enunciação reafirma a hierarquia social (SPIVAK, 2010, p.21).

Por isso, tem sua legitimidade por vários aspectos, mas principalmente por tomar consciência dos sujeitos-protagonistas da/na mudança, após inúmeros danos provocados por instituições como escola, religião e a própria família no processo de constituição de uma identidade; sejam eles, sociais, sexuais ou de gêneros. Ao narrar esta possibilidade, não como um mal em si, mas pela viabilidade de tornar-se um sujeito político, militante e profissional, como bem pontua Bento (2006) os sujeitos só dicotomizam na ficção. A própria narrativa desvela como sua identidade foi produzida pela (i/a)moralidade ou pelas normas de sexo/gênero, ao mesmo tempo que as percebo e abro espaços para relacionar-me com tais mudanças e possibilidades. É dentro destes parâmetros que esta narrativa produz um relato de mim mesma abrindo caminhos para novas experiências. Ao trazer uma linguagem simples e 
direta, o texto pretendeu levar o leitor a compreender em que espaço ou espaços um corpo que subverte as normas de sexo/gênero transitou até tornar-se uma identidade reconhecida por sua própria experiência, num exercício que não traz passividade de leitura, mas busca o desconforto naquele que o lê. Enquanto mulher travesti que vivenciou os trânsitos de gênero e sexualidade em um período histórico em que se começava a problematizar a teoria queer no mundo e no Brasil, lanço mão da reflexão dos impactos dessa teoria na narrativa do buscar-se, adequar-se, (de)limitar para ser normalizada, normatizada, plenamente inserida. Judith Butler (2001, p. 25) diz que,

"não significa suprimir o sujeito, mas apenas se inteirar das condições de sua
formulação e operação", logo,"é a matriz que torna possível toda intenção prévia,
sua condição cultural possibilitadora de compreensões e finalidades".

Então, indago, o que seria essa matriz, para que diante dos meus sentimentos, ações e desejos possa me (re)conhecer como sendo parte dela?

O que é trazido neste ponto mais contundente, e que faz com que pessoas sejam compreendidas dentro do processo binário, é a forma como se dá seu entendimento enquanto privilegiadas, em contrapartida, a compreensão da transexualidade entre os seres. Poderia repensar tais aspectos vivenciados com reflexões contínuas de abuso e estratégias de poder do Estado, por onde padrões cisgêneros binários e heterossexuais mantém e sustentam práticas abusivas sobre pessoas excluídas e que seguem alheias no conhecimentos de si mesmas. A biologia compreende "deformações" como verdades estáticas, uma vez que dentro do processo evolutivo nos compara apenas ao homem hoje conhecido. Tais padrões patologizam para explicar o comportamento humano. Em padrões médicos, quando habilmente se explica masculino e feminino dentro de padrões biológicos, utiliza-se pontos patologizantes, da mesma biologia para inferir grupos sociais marginalizados, como no caso apresentado em tela. Enquanto estrutura político-questionadora, por ser um corpo sexualmente fértil, incluído nas instâncias econômicas do meu país, isto é pagadora de impostos, percebo-me excluída de vários aparatos nas/das políticas públicas, senão por exclusão, por aparência, não contando com a tão sonhada passabilidade. Masculinidades e o masculino, bem como feminilidades e o feminino, são construções sociais e exatamente por isso, pergunto-me, como um ser cisgênero e heterossexual pode significar tanto no mundo material, se as expressões dos praticantes dessa compreensão se versam muito mais com seus pares e iguais, que com seus opostos? Repito, como é possível perceber-se heterossexual nos padrões de produção de realidades que conhecemos, passar o dia cercado por pares semelhantes e ser designado com sendo "praticante" com diferentes? Homens passam o dia trabalhando com seus pares, se divertem com seus pares, riem com seus pares, produzem-se com seus pares, que são outros homens, e 
no final do dia, dormem com suas mulheres. Qual é a complexidade, não compreendida, em perceber o óbvio na ação excludente, ideologizante e patologizante?

O gênero é sempre construído, mesmo não perpassando por recursos que englobam suas sexualidades, mas sempre estarão circundados nas relações de poder pelos sexos impostos, então seja...

\section{Referências}

BENTO, Berenice. A reinvenção do corpo: sexualidade e gênero na experiência transexual. Rio de Janeiro: Garamond, 2006.

BUTLER, J. Corpos que pesam: sobre os limites discursivos do sexo. In: LOURO, Guacira Lopes. (Org.). O corpo educado: pedagogias da sexualidade. 2. ed. Belo Horizonte: Autêntica, 2001.

DE CERTEAU, M. A invenção do cotidiano. Petrópolis: Vozes, 2007.

DELEUZE, Gilles. Conversações. Tradução de Peter Pál Pelbart. São Paulo: Editora 34, 2007.

DESPENTES, Virginie. Teoria King Kong. Tradução de Márcia Bechara. São Paulo: n-1 edições, 2016.

FARGE, Arlette. O sabor do arquivo. São Paulo: Edusp, 2009.

FOUCAULT, Michel. História da sexualidade - A vontade de saber. São Paulo: Graal, 1988.

LOURO, Guacira Lopes. "Pedagogias da Sexualidade". In: . (Org.). O corpo educado: pedagogias da sexualidade. 2. ed. Belo Horizonte: Autêntica, 2001.

SPIVAK, G. C. Pode o subalterno falar? Belo Horizonte: Editora UFMG, 2010.

Recebido em: 01/12/2017

Aceito em: 15/12/2017 